\title{
PHONARTICULATORY DIADOCHOKINESIS IN YOUNG AND ELDERLY INDIVIDUALS
}

\author{
Marina Padovani', Ingrid Gielow², Mara Behlau ${ }^{3}$
}

\begin{abstract}
The phonoarticulatory diadochokinesis test has been recommended to evaluate neurological disorders. It is a speech task that consists of the ability to repeat at high speed a segment of speech. The purpose of this research is to analyze the diadochokinesia rate of adults from two distinct age groups. 23 young adults and 23 elderly people, both sexes participated in this study. Each participant produced the /pa/, / $\mathrm{ta} /, / \mathrm{ka} /$ syllables, the vowel /a/ and the / pataka/ sequence, as fast and as long as they could with habitual pitch and loudness. The speech samples were analyzed by using the voice and speech analysis software VisiPitch III/Sona-Speech, KayElemetrics. Both groups presented with reduced diadochokinesia rate as the speech production became more complex. The young adults group presented with higher diadochokinesia rate in all speech tasks while the elderly adults group had a worse intensity control.
\end{abstract}

KEY WORDS: speech, speech articulation tests, speech production measurement, speech acoustics.

\section{Diadococinesia fonoarticulatória em jovens e idosos}

Resumo - A prova de diadococinesia fonoarticulatória tem sido recomendada para transtornos neurológicos, sendo uma tarefa de fala que consiste na habilidade de realizar rápidas repetições de segmentos de fala. $O$ objetivo deste estudo é analisar a velocidade de diadococinesia em sujeitos adultos em dois grupos etários distintos. Participaram 23 adultos jovens e 23 idosos, de ambos os sexos. Cada indivíduo emitiu as silabas /pa/, $/ \mathrm{ta} /, / \mathrm{ka} /$, a vogal $/ \mathrm{a} /$ e a seqüência / pataka/, o mais rapidamente e durante o maior tempo possivel, em sua freqüência e intensidade habituais. Estas emissões foram analisadas no programa computadorizado de análise de voz e fala Visi-Pitch III/Sona-Speech, da KayElemetrics. Ambos os grupos apresentaram redução da velocidade diadococinética à medida que as emissões foram mais complexas. O grupo mais jovem apresentou velocidade diadococinética maior em todas as emissões enquanto o grupo de idosos teve pior controle de intensidade.

PALAVRAS-CHAVE: fala, testes de articulação da fala, medida de produção da fala,acústica da fala.

The diadochokinesia test is a specific analysis used to examine alternate movements in neurological evaluation. When this task is used in the speech and voice evaluation, it is based on the syllables repetition' and represents the ability of repeating a simple segment of speech at high speed. It constitutes an acoustic index of the articulatory movement and articulators' position rate, thus it is considered as a neurological ability test. The first researches performed on oral diadochokinesia date from the fifths ${ }^{2}$ and investigated individuals with no disorders of any kind. Only from the middle 60s, studies with neurological disorders ${ }^{3}$ began to be developed. The diadochokinesia test can be executed either with a laryngeal focus when the repetition of a vowel is asked or with a speech focus when a syllable repetition is the task for the consonant-vow- el assembling, such as $/ \mathrm{pa} /, / \mathrm{ta} /, / \mathrm{ka} /$ or with different syllables together, for instance /pataka/. Such analysis reflects the neuromotor maturity and integrity of an individual ${ }^{4}$. This index is usually determined by the number of syllables per second. Normal values for $/ \mathrm{pa} /, / \mathrm{ta} /$ and $/ \mathrm{ka} /$ vary from 4 to 6 syllables per second and as the age advances there is a reduction in the syllable number ${ }^{5}$. The impact of aging on voice happens in parallel with other functions of the body and the slowing of speed is one of the most evident characteristics of aging ${ }^{6}$. That can be confirmed by several studies that report a diadochokinesia rate reduction of syllables repetition with age ${ }^{7}$. Moreover, the vocal folds go through structural changes that consist of atrophy, mass decrease, edema and mucosal dehydration ${ }^{8}$. In 1996, a study that investigated individuals

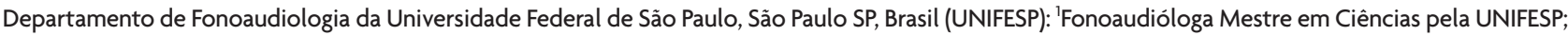
${ }^{2}$ Fonoaudióloga Doutora em Distúrbios da Comunicação Humana pela UNIFESP; ${ }^{3}$ Fonoaudióloga Doutora em Distúrbios da Comunicação Humana pela UNIFESP e Diretora do Centro de Estudos da Voz.
}

Received 18 February 2008, received in final form 29 October 2008. Accepted 10 December 2008. 
with no neurological disorders was performed. Individuals from both sexes aged between 18 to 61 years participated in order to determine normative data for speech motor performance. They utilized the Motor Speech Profile mode of the CSL speech lab, Kay Elemetrics including in this analysis the diadochokinesia test and determined men and women values from the repetition of the /pa/ syllable. In the literature there are reports on speed reduction, worsen of accuracy and inconsistency of oral diadochokinesia in a large range of neurological disorders and even in some functional disorders ${ }^{3,8,10-16}$. Generally, the ataxias seem to produce a greater impact on the diadochokinesia with an important reduction of the speech rate $^{16}$, despite of some differences pointed out in Parkinson's disease ${ }^{15}$. The diadochokinesia test has been correlated with clear articulation ${ }^{3}$, dysartria severity and speech inteligibility ${ }^{13}$. Although it is a relatively simple test, there has not yet been a standardization of its procedures neither of its score determination ${ }^{17}$. Due to the fact that the diadochokinesia test is a task recommended as a neurological scanning, it is necessary to have values standardization of individuals with no disorders in order to establish a normative reference. Therefore, the purposes of this study were to analyze selected diadochokinesia measures by means of diverse speech tasks and to check whether the articulatory and laryngeal diadochokinesia differ young from elderly adults.

\section{METHOD}

The study was carried out at the Human Communication Disorders Department, Speech-Language Program of Universidade Federal de São Paulo and CEV - Centro de Estudos da Voz. The study project was approved by the Ethics Committee of the Universidade Federal de São Paulo, process number 0071/04. Two groups with 23 individuals each participated in this study. One of the groups was composed by 14 females and 9 males, aged between 30 and 46 years, mean age 35.91, median age 36 and the other group by 14 females and 9 males, aged between 47 and 94 years, mean age 70.96, median age 70 .

After reading and signing the Informed Consent each individual was instructed to produce repetitively the syllables $/ \mathrm{pa} /$, $/ \mathrm{ta} /, / \mathrm{ka} /$, the vowel $/ \mathrm{a} /$ and the sequence /pataka/, in the same order, as fast as they managed with comfortable pitch and loudness. Before the execution of the task by the participant, the examiner demonstrated the tasks. Speech samples were recorded into a Sony MDW- 74 Mini Disc, Sony MZ - R30 portable recorder, with a condenser unidirectional microphone Le Son MP 68 placed on a stand at $45^{\circ}$ and at $15 \mathrm{~cm}$ from the mouth in a quiet room. The task performance took approximately 10 minutes.

The recordings were transferred to a Pentium IV, DELL computer and analysed by means of the Visi-Pitch III/Sona-Speech (3900/3600, KAY ELEMETRICS, INC) voice analysis software, in the Motor Speech Profile Module. The diadochokinesia rate was measured to determine the acoustic index of the syllable number per second by means of the peak counting as well as the rate and intensity peak variability. The first eight seconds of each speech sample were used for the analyses.

Five parameters from the eleven available were select for the analysis. The intensity related parameters, expressed in decibels, were not analyzed since the samples recorded by the mini disk could have had values related to this parameter altered.

The parameters selected for the analysis were Average Diadochokinesia Period (DDKavp), in milliseconds. The average period is the average time between consonant-vowel vocalizations (i.e. $/ \mathrm{pa} /$ ). The period is inversely related to the rate. Normative reference mean value of the average syllables duration is $171.18 \mathrm{~ms}$. The second parameter selected was the Average Diadochokinesia Rate. The average rate is the number of consonantvowel vocalizations per second. This rate is inversely related to the average period. Normative mean value of this parameter in the program is 5.89 syllables/second. One of the parameters related to the utterance perturbation was the Coefficient of Variation of Diadochokinesia Period (DDKcrp) in percentage. This parameter measures the degree of rate variation in the period. If the consonant-vowel vocalization is repeated with little variation in rate, then this number is very small. This parameter assesses the individual's ability to maintain constant rate during the syllables repetition. The adequate value considered in the software is $6.00 \%$ of variation of the rate. The other parameter of perturbation is the Perturbations of Diadochokinesia Period (DDKjit) that is expressed also in percentage. This parameter measures the degree of cycle-to-cycle variation in the period and assesses the individual's ability to maintain constant rate of the syllables repetition. The reference value is of $1.25 \%$ of cycleto-cycle variation. The last parameter selected was the Coefficient of Variation of Diadochokinesia Peak Intensity (DDKcvi \%). This parameter measures the degree of intensity variation in the peak of each consonant-vowel vocalization and assesses the individual's ability to maintain constant amplitude of the syllables repetition. Variations of this parameter are considered normal when they do not exceed $1.90 \%$ of mean variation.

The acoustic data was submitted to statistical analysis. SPSS (Statistical Package for Social Sciences), 13.0 version was used. Mann-Whitney test was used to check differences between the two groups. The significance level adopted was $5 \%$.

\section{RESULTS}

Table shows results related to the duration time of syllables in milliseconds, the diadochokinesia rate in syllables per second, the period and cycle-to-cycle rate variation, as well as the intensity peak variation for the five tasks studied.

The young adults group presented with higher vocalization rate when compare to the elderly adults group, except from the vowel /a/ that did not show statistical significant difference for the syllable duration and diado- 
Table. Results obteined.

\begin{tabular}{|c|c|c|c|c|c|}
\hline Parameter and age & PA & TA & KA & A & PATAKA \\
\hline \multicolumn{6}{|l|}{ DDKavp } \\
\hline Young adults & 150.66 & 150.03 & 168.4 & 266.57 & 153.87 \\
\hline Elderly people & 166.45 & 171.75 & 182.31 & 268.01 & 164.19 \\
\hline $\mathrm{p}$ & $<0.001$ & $<0.001$ & 0.002 & 0.818 & 0.015 \\
\hline \multicolumn{6}{|l|}{ DDKavr } \\
\hline Young adults & 6.69 & 6.71 & 6.03 & 3.92 & 6.58 \\
\hline Elderly people & 6.05 & 5.87 & 5.52 & 4.00 & 6.13 \\
\hline $\mathrm{p}$ & $<0.001$ & $<0.001$ & 0.002 & 0.818 & 0.015 \\
\hline \multicolumn{6}{|l|}{ DDKcvp } \\
\hline Young adults & 15.53 & 11.35 & 12.62 & 15.81 & 21.97 \\
\hline Elderly people & 13.66 & 11.76 & 15.36 & 18.67 & 23.57 \\
\hline $\mathrm{p}$ & 0.750 & 0.991 & 0.503 & 0.423 & 0.991 \\
\hline \multicolumn{6}{|l|}{ DDKjit } \\
\hline Young adults & 2.11 & 1.48 & 2.06 & 4 & 4.64 \\
\hline Elderly people & 1.85 & 1.69 & 2.38 & 4.35 & 4.62 \\
\hline $\mathrm{p}$ & 0.503 & 0.223 & 0.448 & 0.560 & 0.684 \\
\hline \multicolumn{6}{|l|}{ DDKcvi } \\
\hline Young adults & 1.01 & 0.82 & 1.19 & 1.09 & 1.81 \\
\hline Elderly people & 2.38 & 2.24 & 2.42 & 1.86 & 3.23 \\
\hline $\mathrm{p}$ & 0.005 & 0.002 & 0.004 & 0.042 & 0.027 \\
\hline
\end{tabular}

Average diadochokinesia period (DDKavp), in ms, average diadochokinesia rate (DDKavr), in syllables per second, coefficient of variation of diadochokinesia period (DDKcvp), in \%, perturbations of diadochokinesia period (DDKjit), in \%, and coefficient of variation of diadochokinesia peak intensity (DDKcvi), in \%, for the repetition of the syllables $/ \mathrm{PA} /, / \mathrm{TA} /, / \mathrm{KA} /$, the vowel $/ \mathrm{A} /$ and the sequence /PATAKA/, of young and elderly adults. All speech productions were statistically different, except from the vowel $/ a /$ for the period and rate measure (DDKavp and DDKavr). For the perturbation parameters, only the peak intensity variation (DDKcvi) presented with statistically significant differences in all speech production.

chokinesia rate. We observed that rate changes and varies according to the produced syllable and it reduces as the articulatory point goes backward. The rate variation did not significantly vary with age; however the intensity peak had great variation in all tasks for the elderly adults.

\section{DISCUSSION}

The diadochokinesia test has been suggested as a sensitive analysis for motor ruptures, especially for the ones of neurological nature. Due to the fact that this analysis does not suffer the influence of language properties, it may have a universal use for characterizing speech motor disorders. The information derived from these tasks may help as a basic reference for the interpretation of more complex tasks. Besides, more detailed analysis of this test that includes temporal and amplitude variability can provide useful information for the comprehension of pathophysiological processes ${ }^{14}$. However, before checking for the sensitiveness of this task for the speech motor disorders, it is important to know the behavior of individuals without such disorder to produce references for comparisons.

In the present study there was a progressive reduction of the number of syllables per second as the utterances went more posteriorly in the oral cavity. This phenomenon may be explained by the fact that there may be less effort to produce labial phonemes, which increases progressively to the tip and back of the tongue. In parallel with it, there is a crescent increase of VOT as the articulatory point goes backwards into the vocal tract. We can also reason about the involvement of other muscle groups for those tasks. For the $/ \mathrm{pa} /$ production, only the orbicular muscle is involved while for the other phonemes with tongue tip and back and larynx movements several other muscles are requested ${ }^{18,19}$. Therefore, the reduction of diadochokinesia rate with the increase of the task complexity may seem to be a typical vocal tract behavior.

There were no differences between the groups as far as rate variability is concerned and that is probably because the individuals were healthy. However, when considering the peak intensity, the elderly adults group presented with great variability, which reflects difficulty with controlling intensity, probably due to the deviation inherent to the aging process such as spindled shape glottal chink ${ }^{20}$ and the intrinsic laryngeal muscles atrophy that results in less biomechanical efficiency of the whole system ${ }^{21}$.

We conclude that the diadochokinesia test was re- 
sponsive to distinguish between young and elderly adults during the production of $/ \mathrm{pa} /, / \mathrm{ta} / \mathrm{e} / \mathrm{ka} /$ for the parameters of average diadochokinesia period, average diadochokinesia rate, variation of diadochokinesia peak intensity; however the laryngeal diadochokinesia did not differentiate the two groups, which highlights the impact of the aging on speech. Both groups presented with diadochokinesia rate reduction as the utterances became more complex that characterizes the human vocal tract behavior.

\section{REFERENCES}

1. Kent RD, Weismer G, Kent JF, Vorperian HK, Duffy JR. Acoustic studies of dysarthric speech: methods, progress and potential. J Commun Disord 1999;32:141-186.

2. Lundeen DJ. The relationship of diadochokinesis to various speech sounds. J Speech Hear Disord 1950;15:54-59.

3. Canter GJ. Speech characteristics of patients with Parkinson's disease: III. Articulation, diadochokinesis, and overall speech adequacy. J Speech Hear Disord 1965;30:217-224.

4. Baken RJ. Clinical measurement of speech and voice. Boston: ColegeHill Press, 1987:445-452.

5. Behlau, M (org). Voz, o livro do especialista Vol 1. Rio de Janeiro: Revinter, 2001:91-111.

6. Welford AT. Skill and age: an experimental approach. London: Oxford University Press, 1951:98.

7. Ptacek PH, Sanders EK, Maloney WH, Jackson CR. Phonatory and related changes with advanced age. J Speech Hear Res 1966;9:353-960.

8. Aronson AE. Clinical voice disorders: an interdisciplinary approach. New York: Thieme, 1990.
9. Deliyski D, Gress CD. Characteristics of motor speech performance normative data. Instructional Manual Visi-Pitch III/Sona-Speech Model 3900/3600, Lincoln Park, 1996.

10. Kreul EJ. Neuromuscular control examination (NMC) for parkinsonism vowel prolongations and diadochokinetic and reading rates. J Speech Hear Res 1972;15:72-83.

11. Mulligan M, Carpenter J, Riddel J, Delaney MK, Badger G, Tandan PKR Intelligibility and the acoustic characteristics of speech in amyotrophic lateral sclerosis (ALS). J Speech Hear Res 1994;37:496-503.

12. Boutsen FR, Gress CD, Deliyski DD. Automated assessment of motor speech performance in basal ganglia disorders. Anais ASHA, Seattle, 1996.

13. Ziegler W, Wessel K. Speech timing in ataxic disorders: sentence production and rapid repetitive articulation. Neurology 1996;47:208-214.

14. Kent RD, Kent JF,Duffy JR, Thomas JE, Weismer G, Stuntebeck S. Ataxic dysarthria. J Speech, Language Hear Res 2000;43:1275-1289.

15. Carrara-de-Angelis E. Deglutição, configuração laríngea, análise clínica e acústica computadorizada da voz de pacientes com doença de Parkinson. Tese Doutorado. São Paulo: UNIFESP, 2000.

16. Ziegler W. Task-related factors in oral motor control: speech and oral diadochokinesis in dysarthria and apraxia of speech. Brain Language 2002;80:556-575.

17. Baken RJ, Orlikoff R. Clinical measurements of speech and voice. 2nd ed. San Diego: Singular, 2000.

18. Prathanee B. Oral diadochokinetic rate in adults. J Med Assoc Thai 1998 81:784-787.

19. Seikel JA, King DW, Drumright DG. Anatomy and physiology for speech, language and hearing. San Diego: Singular, 1997.

20. Honjo I, Isshiki N. Laryngoscopic and vocal characterisitics of aged persons. Osaka: Kansai Medical Uiversity, 1979.

21. Morrison M, Rammage LA, Nichol H. Evaluation and management of voice disorders in the elderly. In: Goldstein JG, Kashima HK, Koopmann CV JR(eds). Geriatric otorhinolaryngology. Philadelphia: Decker, 1989. 